\section{Medical Subject Headings}

IT has been announced that Medical Subject Headings, the cross-reference guide to the Index Medicus and the medical subject heading authority list published annually by the National Library of Medicine, is to be significantly revised. The 1965 issues will contain 579 additional indexing terms, making an overall total of 6,380 . The new terminology will be concerned with the following categories: anatomy (category $A$ ); diseases (category $C$ ); chemicals and drugs (category $D$ ); and analytical, diagnostic, and therapeutic technology and equipment (category $E$ ). These terms reflect the content of 222 journals which were previously not covered by Index Medicus. A total of 208 other journals are being deleted from the Index Medicus list. The newly indexed journals cover the fields of dontistry, chemistry, psychology, sociology and veterinary medicine. Indexing terms in Medical Subject Headings will continue to appear in alphabetical and categorical lists. Although the format will not change, the alphabetical list will be composed for the first time in upper and lower case letters by $G R A C E$ - 'Graphic Arts Composing Equipment'-a component of the Library's computer system. Medical Subject Headings will be published as Part 2 of the January 1965 Index Medicus. Yoarly subseriptions to Index Medicus are available from the Supcrintendent of Documents, Government Printing Office, Washington, D.C., at 40 dollars (9 dollars additional for foreign posting). Single issucs of Index Medicus are available at 3.75 dollars and single copies of Medical Subject Headings at 2.50 dollars.

\section{Research on Immunology}

All scientists are nowadays aware of the rapid growth and incroasing range and importance of research related to immunology, Woxld Health Organization Technical Report No. 286 records the views of the members of five intornational groups convoned by the Organization to consider various aspects of this subject (Research in Immunology. Pp. 97. Geneva: World Health Organiza. tion; London: H.M.S.O., 1964, $5 \mathrm{Sw}$. francs; 8s. 6d.; 1.75 dollars). The views expressed do not necessarily represent the views of tho Organization or its policy. The subject is discussed under the following five headings; immunoprophylaxis and immunotherapy; immunopathology; tissue antigens and transplantation; immunochemistry; a final section entitled "Programme in Immunology", which includes sections on the training of immunologists and recommondations for research.

\section{Programmed Instruction Book on Semiconductor Devices}

A NEW linear programmed instruction book on semiconductor devices has been published by the Mullard Educational Service. It is based on information proviously published by the Service as $A$ Simple Explanation of Semiconductor Devices. The book treats the subject in a non-mathematical way, emphasis being given to the physical aspects of electron and hole conduction. A supplementary booklet containing coloured diagrams illustrating semiconductor action is contained at the back of the book. This supplement is referred to by the reader as he progresses through the programme. In a programmed instruction book of this kind the subject is broken down into many small numbered units called frames. Fach frame requires from the reader a written response which is compared with the model answer given alongside the frame. The reader goes through the programme at the rate which he finds most natural an advantage of this new system of learning. A short test included at the back of the book should be attempted before and after com. pleting the programmo. In this way the reader is able to assess how much he has learnt from the book. Copies of the book (price 3s. 6d. including supplement) are available from the Mullard Educational Service, Mullard House, Torrington Place, London, W.C.1.

\section{High-speed Photography}

Barr and Stroud manufacture two ultra-high-speed cameras, the 'CP5 Framing Camera' and the 'CP6 Streak Camera'. 'The 'CP5 Framing Camera' uses the Miller system of optics. The image of the event formed by an objective lens is focused on the surface of a rotating mirror. The light reflected from the rotating mirror sweeps across a number of lenses arranged in an arc, which focus the image on the mirror on to a strip of film. Several different optical systems are available for different framing rates and numbers of pictures. One system, for example, enables 117 pictures, $8 \mathrm{~mm}$ diameter, to be taken at $8 \times 10^{6}$ pictures per second with an exposure time of 0.12 usee per picture. Facilities are available for synchronizing the camera and the event and for terminating the exposure. A camera of this type was used for the work described in Nature, 202,$443 ; 1964$. The 'CP6 Stroak Camera' consists of an objective lens which focuses the image of the event on a narrow slit, which is focused by a second lens on to an are of film via a rotating mirror, which sweeps the image of the slit along the film. The maximum writing speed is $22 \mathrm{~mm} / \mu$ sec with a recording time of 27 usec. Using a $0.05 \mathrm{~mm}$ slit a time resolution of $10^{-6}$ sec is possible. The facilities for synchronization and capping are similar to those of the framing camera.

\section{Announcements}

Mr. Austen Albu, M.P., has been appointed as a member of the Medical Research Council. Mr. Albu is a Governor of both the Imperial College of Science and Technology and Battersea College of Technology. He has been chairman of the Parliamentary and Scientific Committee since 1962.

Prof, A. G. WARd, head of the Procter Department of Food and Leather Seience in the University of Leeds, has been appointed chairman of the U.K. Food Standards Committee for a period of three years as from January 1 in suecession to Mr. M. W. Perrin, who is giving up the appointment because of pressure of work and other commitments.

THe seventh Castner memorial lecture entitled "Some Achievements in Petroleum Chemicals" will be delivered in London by Dr. H. M. Stanley on March 8. Further information can be obtained from the Society of Chemical Industry, 14 Belgrave Square, London, S.W.1.

A sxmpostum on "The Formulation of Pesticides", arranged under the auspices of the Pesticides Group and the Colloid and Surface Chemistry Group of the Society of Chemical Industry, will be held at the School of Pharmacy, London, during March 30-31. Further information can be obtained from the Honorary Socretary of the symposium, Society of Chemical Industry, 14 Belgrave Square, London, S.W.1.

THs nineteenth annual symposium on fundamental cancer research on "Developmental and Metabolic Control Mechanisms and Neoplasia" will be held in the University of Texas during March 4-6. Topics under discussion will include: biosynthesis and control mechanisms; molecular basis of early development; molecular basis of later development and control; comparative studies on control mechanisms in normal and neoplastic tissues. Further information can be obtained from Dr. D. N. Ward, Department of Biochemistry, University of Texas M. D. Anderson Hospital and Tumor Institute, Houston 25, Texns.

ERRATUM. The communication entitled "Iron-deficient Low-temperature Pyrrhotite", which appeared on p. 175 of the October 10, 1964, issue of Nature, is by F.J. Sawkins, Dr. A. C. Dunham and Dr, D. M. Hirst, and not F. J. Sawkins, Prof. A. C. Dunham, F.R.S., . . as stated in the contents page of that issue. 